\title{
Synergistic applications of autonomous underwater vehicles and regional ocean modeling system in coastal ocean forecasting
}

\author{
Yi Chao ${ }^{1}$ and Zhijin $\mathrm{Li}$
}

Jet Propulsion Laboratory, California Institute of Technology, 4800 Oak Grove Drive, Pasadena, California 91109

\section{John D. Farrara}

Raytheon Information Solutions, Pasadena, California 91101; Jet Propulsion Laboratory, California Institute of Technology, 4800 Oak Grove Drive, Pasadena, California 91109

Mark A. Moline

Biological Sciences Department and Center for Coastal Marine Sciences, California Polytechnic State University, San Luis Obispo, California 93407

Oscar M. E. Schofield

Institute of Marine and Coastal Sciences and Coastal Ocean Observation Laboratory, Rutgers University, New Brunswick, New Jersey 08903

\section{Sharanya J. Majumdar}

RSMAS Division of Meteorology and Physical Oceanography, University of Miami, Miami, Florida 33149

\begin{abstract}
The potential for using synergistic combinations of measurements from autonomous underwater vehicles (AUVs) and output from three-dimensional numerical models for studying the central California coastal region is demonstrated. Two case studies are used to illustrate the approach. In the first, propeller-driven AUV observations revealed a subsurface salinity minimum in northern Monterey Bay. A Regional Ocean Modeling System (ROMS) reanalysis of the three-dimensional flow in the region suggested an offshore source for this water and particular propagation pathways from the south and west into the bay. In the second case study, the effectiveness of assimilating observations in improving the ROMS reanalysis fields is investigated. A significant improvement, especially in the salinity fields, is demonstrated through a single glider deployed outside the intensive observational domain. These results suggest that investigation of more sophisticated techniques for using data and models together is warranted. Such techniques include increasing model resolution in areas of interest identified by observing platforms and using model-based "targeted observing" techniques to identify areas of uncertainty in the flow to guide placement of observational assets.
\end{abstract}

Observations that adequately sample the three-dimensional (3D) structure of the coastal ocean are very sparse.

\footnotetext{
${ }^{1}$ Corresponding author (Yi.Chao@jpl.nasa.gov).

Acknowledgments

The research described in this paper was carried out, in part, at the Jet Propulsion Laboratory (JPL), California Institute of Technology, under contract with the National Aeronautics and Space Administration. Computing support from the JPL Supercomputing Project is acknowledged. Thanks to James C. McWilliams and his team for their help with the model. The contributions of Peggy Li, Kyungjeen Park, Quoc Vu, Xiaochun Wang, and Carrie Zhang to the model operation during and after the 2003 and 2006 Monterey Bay field experiments are acknowledged. Thanks to Shelley Blackwell and Ian Robbins at California Polytechnic State University at San Luis Obispo for providing support for autonomous underwater vehicle deployments and glider deployments, respectively. The original high-frequency radar data were supplied by Jeffrey Paduan at the Naval Postgraduate School. The M1 mooring data were provided by Francisco Chavez at the Monterey Bay Aquarium Research Institute.
}

Traditional oceanographic measurements include either in situ or satellite observations. In situ measurements are mostly one dimensional (1D) at a single point (e.g., drifters or moorings) or two dimensional (2D) through a cross section (a ship track). Satellite instruments can provide a greatly increased number of observations and coverage, but their measurements still provide a $2 \mathrm{D}$ view of the ocean surface. Using these 1D or 2D observations, we can only infer or speculate on the complex 3D structure of the ocean.

Recent development of Autonomous and Lagrangian Platforms and Sensors (ALPS) opens a new opportunity to observe the 3D structure of the ocean. Over a limited area of interest, a fleet of ALPS (e.g., gliders) has the potential of mapping this 3D structure on synoptic time scales. The Autonomous Ocean Sampling Network (AOSN) field experiment (Curtin et al. 1993) conducted in the Monterey Bay, California, during August 2000 demonstrated the feasibility of glider technology in making routine oceanographic measurements. A follow-on field experiment, known as AOSN-II, deployed a fleet of more than a dozen gliders in the Monterey Bay in an attempt to monitor and 
trace sources of the water during upwelling and downwelling (or relaxation) events during August 2003. During this effort, glider data were transmitted in real time to a centralized data server for distribution to both participating investigators as well as two operational 3D ocean circulation models (i.e., the Regional Ocean Modeling System presented in this study and the Harvard Ocean Prediction System).

As part of the Integrated Ocean Observing System (IOOS), operational ocean modeling and data assimilation have promised an alternative way to obtain a detailed description of the 3D structure of the coastal ocean. Meteorologists have been using this approach for decades to produce $3 \mathrm{D}$ snapshots of the atmosphere. Furthermore, numerical atmospheric and oceanic models, when initialized with measurements, have the ability to make forecasts into the near future. For weather forecasts, it is possible to predict the future evolution of the $3 \mathrm{D}$ atmosphere for about a week to $10 \mathrm{~d}$. The open ocean variability that is associated with the El Niño and Southern Oscillation phenomena can also be predicted on seasonal to interannual time scales (Cane et al. 1986). However, the predictability of the coastal ocean still remains to be explored (Yoder et al. 1987; Lovejoy et al. 2001; Chang et al. 2002).

While predicting the 3D coastal ocean is a long-term goal, this paper attempts to present our initial results to combine ALPS data with 3D assimilative models, similar to Besiktepe et al. (2003), with an aim to describe the 3D coastal ocean. Two primary questions will be addressed here. Is the numerical model good enough to realistically reproduce 3D coastal ocean flow structures? What is the effect of ALPS data on the model analyses and forecast? We approach these questions through two case studies conducted using data from two different field experiments in Monterey Bay. Although we use other sources of data during the experiments, the case studies here focus on the use of REMUS AUV (Moline et al. 2005) and Slocum glider observations, together with analyses produced by the Regional Ocean Modeling System (ROMS) model data assimilation system. A longer-term goal is to use assimilative ROMS to optimize or refine the ocean observing system.

The paper is organized as follows. First, the observational platforms, the data gathered, and the ocean model used are described. Second, the first case study is presented and consists of a validation of the model reanalysis used as the basis for the subsequent data-model comparisons. Third, we examine the particular salinity distribution observed and explore a possible source and the propagation pathways for the observed subsurface salinity minimum. Fourth, the second case study on the effect of glider data during the early part of the Adaptive Sampling and Prediction (ASAP) field experiment in 2006 (Zhang and Leonard 2007) is described. Finally, a summary and concluding remarks are presented.

\section{Methods}

The first field experiment, AOSN-II, was conducted during August 2003 (Leonard et al. 2007). This experiment brought together a variety of observational instruments (both in situ and remote), data-assimilating numerical models, and adaptive sampling tools to guide the deployment of the observational assets. The in situ platforms included fixed (e.g., ships, moorings) and mobile platforms (e.g., ships, gliders, AUVs), while the satellite data included temperatures from both infrared and microwave sensors, ocean surface winds from radar scatterometer, and sea surface heights from radar altimeter. In addition to ROMS that provided real-time forecast fields during the field experiment, the NCOM (NRL Coastal Ocean Model) and HOPS (Harvard Ocean Prediction System) were also run in real time. The adaptive sampling tools include the glider control software and the Ensemble Transform Kalman Filter (ETKF)-based prediction. The close coupling of the data gathered with the numerical model analyses and forecasts constituted a unique test bed for investigating oceanographic phenomena in the region. In the first case study using AOSN-II data, we analyze a distinct subsurface salinity minimum within the bay observed by a REMUS AUV (Moline et al. 2005). We use this observed data in conjunction with the ROMS reanalysis of the circulation in an attempt to understand the formation of this structure, the source of the lower salinity water, and the dominant propagation pathways.

Building on the success of the 2003 AOSN-II experiment, a second field experiment, ASAP (Zhang and Leonard 2007), part of a much larger Monterey Bay 2006 coordinated field experiments (known as MB06), was conducted during August 2006. For the ASAP experiment, the paths taken by the gliders were somewhat more complex than during the AOSN-II 2003 experiment. The scientific focus of ASAP was to gain a thorough understanding of the 3D dynamics of the Point Año Nuevo upwelling center (Leonard et al. 2007). To achieve this objective, a large number of the available observation assets were deployed within this area. Since conditions in the Point Año Nuevo region were affected by the largerscale flow outside the region, this sampling strategy was not optimal for the data-assimilating numerical models. Therefore, it was decided at the beginning of the experiment to deploy an additional glider in an area outside the region to examine the effect of remote forcing by providing data on the larger scales for the numerical models. We present here the effect of including data from this additional glider in the assimilation that produced the ROMS reanalysis for the first week of August 2006.

REMUS AUV and Slocum glider-During the AOSN-II experiment, a REMUS AUV was operated every night in Monterey Bay from 10 to 17 August 2003 (see Fig. 1A,B). While the other mobile assets in the larger experiment were changing location during the experiment, the REMUS AUV operated repeatedly along a single transect to provide the temporal and spatial evolution of the physical environment for comparison with the ROMS model. Detailed background information on the vehicle and vehicle performance is provided in Moline et al. (2005, in press) and Blackwell et al. (2008). The vehicle was configured with an Ocean Sensors OS-200 CTD collecting 

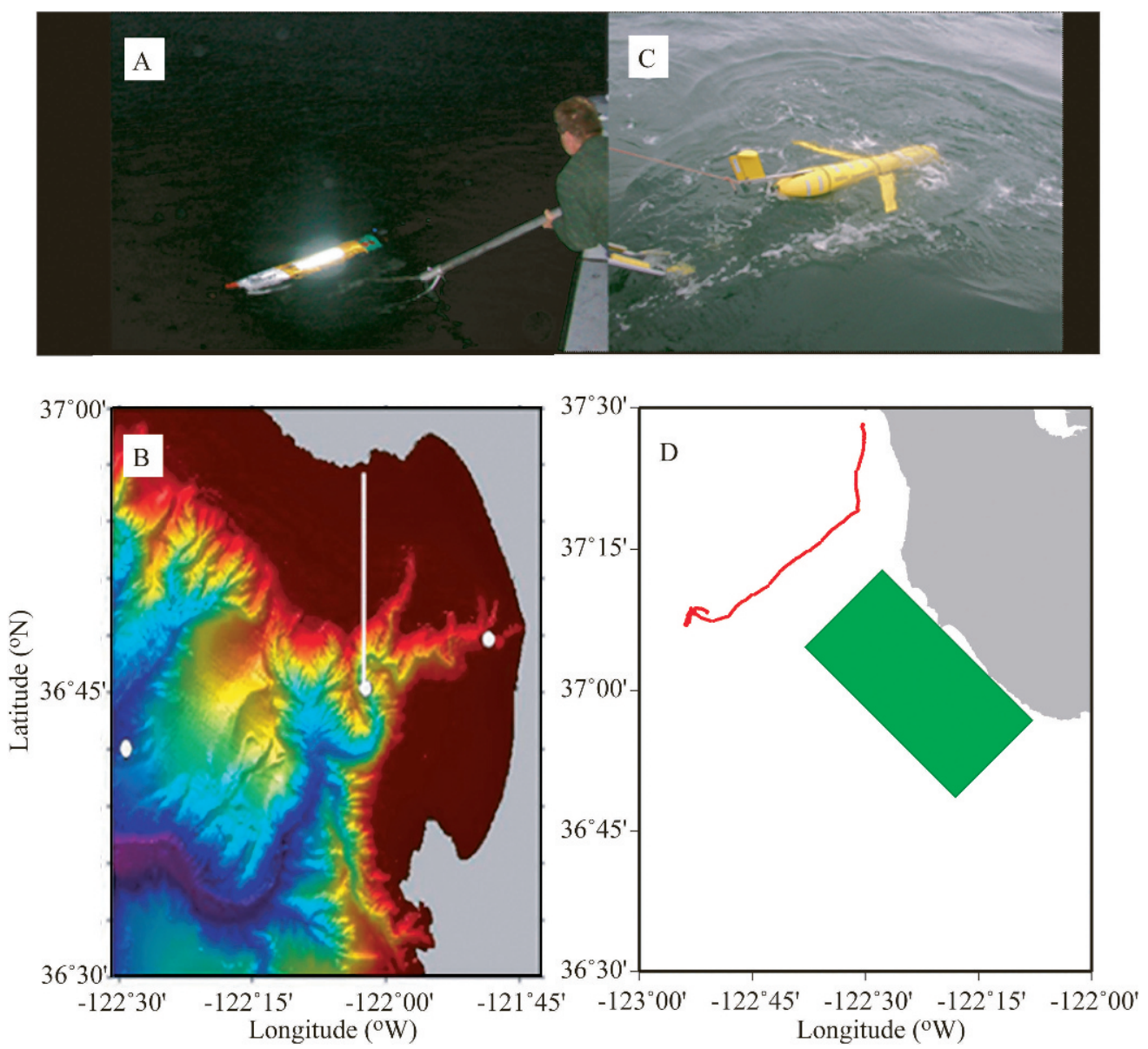

Fig. 1. (A) The night time recovery of the REMUS AUV during the AOSN II experiment in Monterey Bay in August 2003. (B) Location of the REMUS AUV deployment in Monterey Bay in August 2003. Filled white circles represent the location of the MBARI mooring array with M1 being at the south end of the AUV transect. (C) Deployment of the CalPoly Slocum glider off Half Moon Bay, California, for the ASAP experiment in August 2006. (D) Red line indicates the track of the CalPoly glider and source of the T and S data for the modeling effort during the first week of August 2006. Also shown (green box) is the ASAP area of intensive ALPS observations.

data at $2 \mathrm{~Hz}$ with a nominal vehicle speed of $1.7 \mathrm{~m} \mathrm{~s}^{-1}$, yielding a horizontal data resolution of $0.85 \mathrm{~m}$ for the optical measurements. The additional sensors were housed in a $30-\mathrm{cm}$ module forward of the ADCP and included a Seapoint fluorometer, a Seapoint backscatter sensor, and a bioluminescence bathyphotometer. The measure of bioluminescence required that the deployments and recoveries during this experiment occur at night (see Fig. 1).

The REMUS AUV used two modes of navigation to complete the missions in Monterey Bay. Conventionally, the vehicle operates within an array of digital acoustic transponders deployed in the area of study for the duration of a mission. Long baseline (LBL) navigation is based on the principles of triangulation. The latitude and longitude of each of the transponders is preprogrammed into the REMUS mission file. The vehicle calculates its position by computing its range to the acoustic transponders with a maximum range of $2.5 \mathrm{~km}$ every $4 \mathrm{~s}$. During periods between triangulated fixes or when acoustic fixes are not available, the vehicle navigates in Dead Reckoning (DR) mode, relying on compass heading and last known position to navigate to its next programmed waypoint. REMUS incorporates ocean current velocity, vehicle velocity (based on propeller revolutions per minute and bottom-tracking Doppler signals), and heading information to estimate its location and navigate accordingly. DR navigational accuracy depends on oceanic conditions and the $\sim 2.3^{\circ}$ error in the vehicle's magnetic compass (Moline et al. 2005).

During this study, the vehicle's traditional LBL acoustic navigation nearshore was supplemented with DR to increase the operational range of the vehicle in order to survey a larger area of Monterey Bay. The vehicle was programmed to first run a series of four $500-\mathrm{m}$ lines spaced $20 \mathrm{~m}$ apart along the same intended $180^{\circ}$ heading of the transect mission across the bay. These initial four lines allowed the vehicle, while still in range of the acoustic transponders, to correct for any compass error before setting off on the $45-\mathrm{km}$ offshore transect. On nine consecutive nights during 10-18 August 2003, the vehicle navigated $20 \mathrm{~km}$ offshore from Santa Cruz, California, to the M1 mooring at the center of Monterey Bay (Fig. 1; Chavez et al. 1997), undulating between 3 and $40 \mathrm{~m}$. The vehicle then made a $150^{\circ}$ turn to the northeast and 


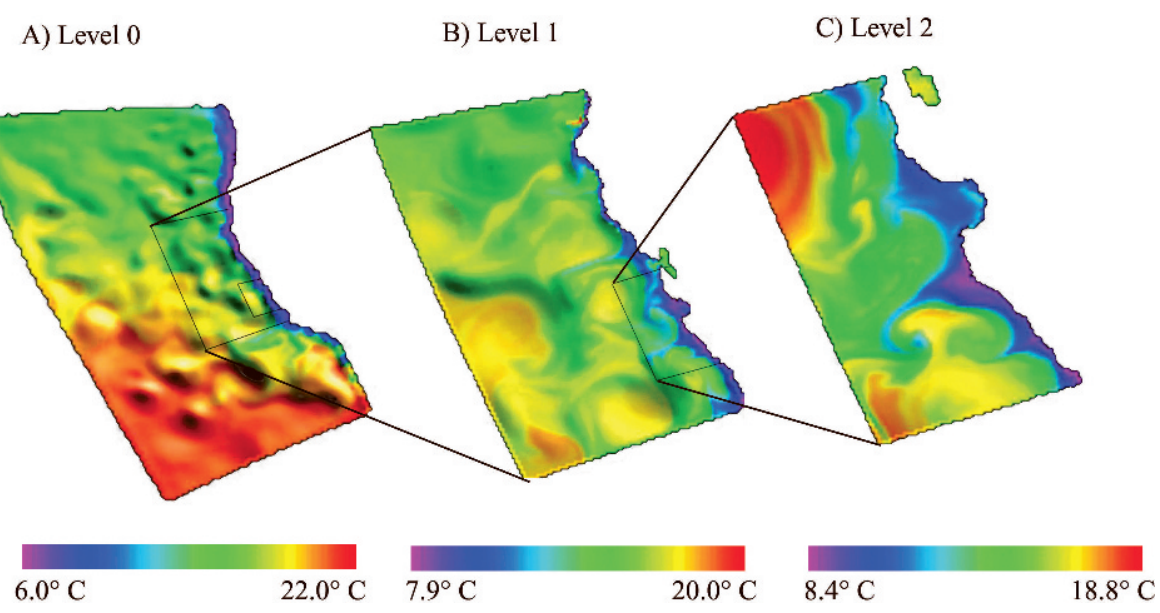

Fig. 2. A nested ROMS configuration with (A) the U.S. West Coast ROMS at $15 \mathrm{~km}$, (B) the central California coastal ROMS at $5 \mathrm{~km}$, and $(\mathrm{C})$ the Monterey Bay ROMS at $1.5 \mathrm{~km}$.

continued to the shore, where it was retrieved. After the return of the vehicle, data from the vehicle were retrieved and sent to JPL for assimilation into ROMS within $1 \mathrm{~h}$.

The nonpropeller Webb Slocum Electric Glider (Fig. 1C; Schofield et al. 2002), belonging to the Rutgers University Coastal Ocean Observation Laboratory (RU COOL), was deployed from Half Moon Bay, California, on 02 August. It operated continuously until 17 September 2006, except for one 6-h turnaround on 24 August for replacing the battery packs. The glider is an autonomous vehicle that moves up and down in the ocean by altering its buoyancy by a piston-driven air-filled bladder. Wings allow horizontal propulsion, and a tail rudder allows for steerable gliding. This vehicle traces a sawtooth profile, observing temperature, salinity, and depth using custom SBE CTD modeled off the MicroCAT CTD. The glider's nominal mission profile for this study consisted of a series of undulations to $60 \mathrm{~m}$ with an average cast taking $\sim 20 \mathrm{~min}$ and a surfacing interval every $3 \mathrm{~h}$. At the surface, the glider obtained a GPS fix and iridium telephone links through a tail-mounted transmitter and receiver. Once communications were established, position and sensor data from vehicle were sent in real time to the glider operations center at RU COOL and Cal Poly (Schofield et al. 2007). After a quality control check, they were available for model assimilation. The sequence of events from glider surfacing to data available for model assimilation took no longer than $5 \mathrm{~min}$. The glider operations center also provided new tasking to the glider on the surface if needed in coordination and feedback from the larger ASAP team. Over the 45-d deployment, the glider collected 3563 CTD casts to the northern side of the ASAP study area (Fig. 1D).

ROMS - The model is based on the ROMS, which solves the primitive equations using the Boussinesq and hydrostatic approximations in vertical sigma (i.e., topography following) and horizontal orthogonal curvilinear coordinates. ROMS uses innovative algorithms for advection, mixing, pressure gradient, vertical-mode coupling, time stepping, and parallel efficiency (Shchepetkin and McWilliams 1998, 2005).

This study uses a nested ROMS configuration with increasing resolution covering the U.S. west coastal ocean at $15 \mathrm{~km}$, the central California coastal ocean at $5 \mathrm{~km}$, and the Monterey Bay region at $1.5 \mathrm{~km}$. Figure 2 shows the three nested domains using a snapshot of sea surface temperature and sea surface height to illustrate the different scales of motion resolved by the different domains. All three domains have 32 vertical sigma layers. The three nested ROMS domains shown in Fig. 2 are coupled online (using the OpenMP programming language on a sharedmemory parallel computer) and run simultaneously exchanging boundary conditions at every time step of the coarser resolution domain.

The hourly atmospheric forcing fields provided by the Fleet Numerical Meteorology and Oceanography Center's Coupled Ocean-Atmosphere Mesoscale Prediction System (Hodur and Doyle 1999) were used as the atmospheric forcing. All the temperature and salinity observations available (surface and vertical profiles) were assimilated using a 3D variational (3DVAR) data assimilation scheme. During the reanalysis phase, the surface current data from the high-frequency (HF) radar were also assimilated. Our ROMS 3DVAR follows closely that used in the meteorological data assimilation community, but we have proposed particular strategies that are unique for oceanographic applications. These strategies include the implementation of 3D anisotropic and inhomogeneous 3D error correlations based on a Kronecker product, application of particular weak dynamic constraints, and implementation of efficient and reliable algorithms for minimizing the cost function. The detailed algorithm and its implementation are reported in two companion papers ( $\mathrm{Li}$ et al. 2008, in press).

\section{Results}

During the AOSN-II experiment, analyses of the ocean state (also known as nowcasts) were produced every $24 \mathrm{~h}$. After the experiment, a number of upgrades were made to 

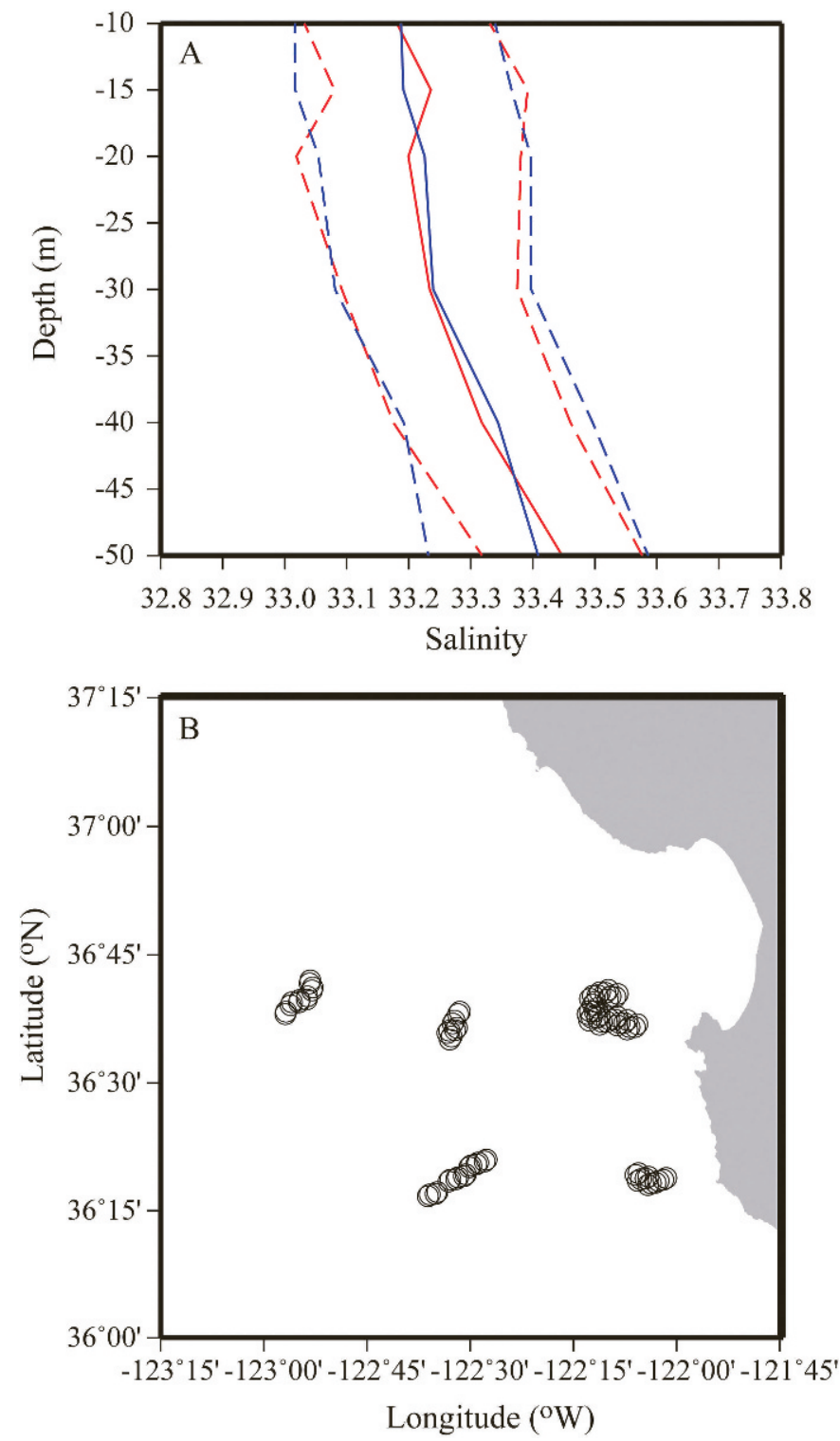

Fig. 3. Comparison of vertical salinity profiles between the glider measurements (red) and colocated ROMS reanalyses (blue) for 07 August 2003 at all glider locations. Mean vertical salinity profiles are shown in solid lines, and the one-standard-deviation curves are shown in dashed lines.

the system: more data were added with more careful quality control procedures, and improvements were made in the data assimilation scheme as well as the model boundary conditions. A reanalysis that produced fields every $6 \mathrm{~h}$ was then performed, and it is this reanalysis that is used here.

Model validation - Before we use the model simulation to perform process studies investigating the salinity distribution and its propagation pathways, it is essential to verify the accuracy of the model simulated salinity fields against the existing observations. A systematic validation of the model simulation is beyond the scope of this manuscript and will be published in a separate paper. This section presents only a brief summary of the overall model performance.
As described previously, all the temperature and salinity measurements from the gliders deployed as part of the AOSN-II experiment in the Monterey Bay area are assimilated into ROMS. Because the ROMS data assimilation system is constructed as a weak constraint, it is still useful to compare the ROMS reanalysis against these glider measurements. Although these glider measurements do not represent an independent data set, they do act as a consistency check on the reanalysis.

Figure 3 shows the mean salinity profile (for the depth range $0-50 \mathrm{~m}$ ) for 07 August from all available gliders located to the south and west of Monterey Bay and the colocated reanalysis values. Also shown are the locations of the gliders and dashed lines representing plus and minus one standard deviation for both observations and the reanalysis. Figure 4 shows the correlation and root-meansquare (RMS) errors calculated between the glider measurements and ROMS reanalysis as a function of depth $(0$ $50 \mathrm{~m}$ ). The RMS values are quite small, ranging from less than 0.05 at $10 \mathrm{~m}$ to about 0.1 at $30 \mathrm{~m}$. The correlations are uniformly high, greater than 0.75 at all depths. The major discrepancy is observed near the bottom of the surface mixed layer. This discrepancy is mostly due to the vertical mixing parameterization and the limited vertical resolution near the surface. There also appears to be a bias in the deep ocean, probably because of the need for more accurate side boundary conditions. The overall picture that emerges is that the lower salinity values to the south and west of the bay found in the reanalysis are realistic. It remains to be determined to what extent these freshwaters are generated by the model physics or, at least in part, by the assimilation of hydrographic salinity data.

Because we are assimilating only the surface HF radar data into the ROMS reanalysis, it is important to use an independent subsurface velocity data set to assess the quality of the ROMS reanalysis. Figure 5 shows the meridional currents as a function of depth $(0-50 \mathrm{~m})$ and time (for the entire month of August 2003) as observed by the ADCP at the M1 mooring (Fig. 1; near $36.76^{\circ} \mathrm{N}$, $122.0^{\circ} \mathrm{W}$ ) located in the center of the Monterey Bay and the colocated ROMS reanalysis. Note that there are no ADCP measurements between the surface and $20 \mathrm{~m}$. Overall, the reanalysis (Fig. 5B) reproduces the time evolution revealed by the ADCP. This evolution is characterized by generally northward flow early in the month that is replaced by equatorward flow as the upwelling event reaches its peak, then a brief return of poleward flow during the relaxation period (20-24 August), and finally equatorward flow for the rest of the month as upwelling returns. Focusing on the early August period, we see that the M1 ADCP (upper panel) shows poleward flow between 20 and $50 \mathrm{~m}$ that develops on 05 August and decays by 10 August. The reanalysis (middle panel) shows a very similar time evolution, though below $20 \mathrm{~m}$ the poleward flow persists somewhat longer in the reanalysis. In addition, the M1 ADCP shows values as large as $15 \mathrm{~cm} \mathrm{~s}^{-1}$, while the reanalysis has values that are somewhat smaller. Note also that in the reanalysis, the poleward flow is much weaker near the surface $(0-10 \mathrm{~m})$ than below. Although the velocity comparison shows less impressive agreement than 

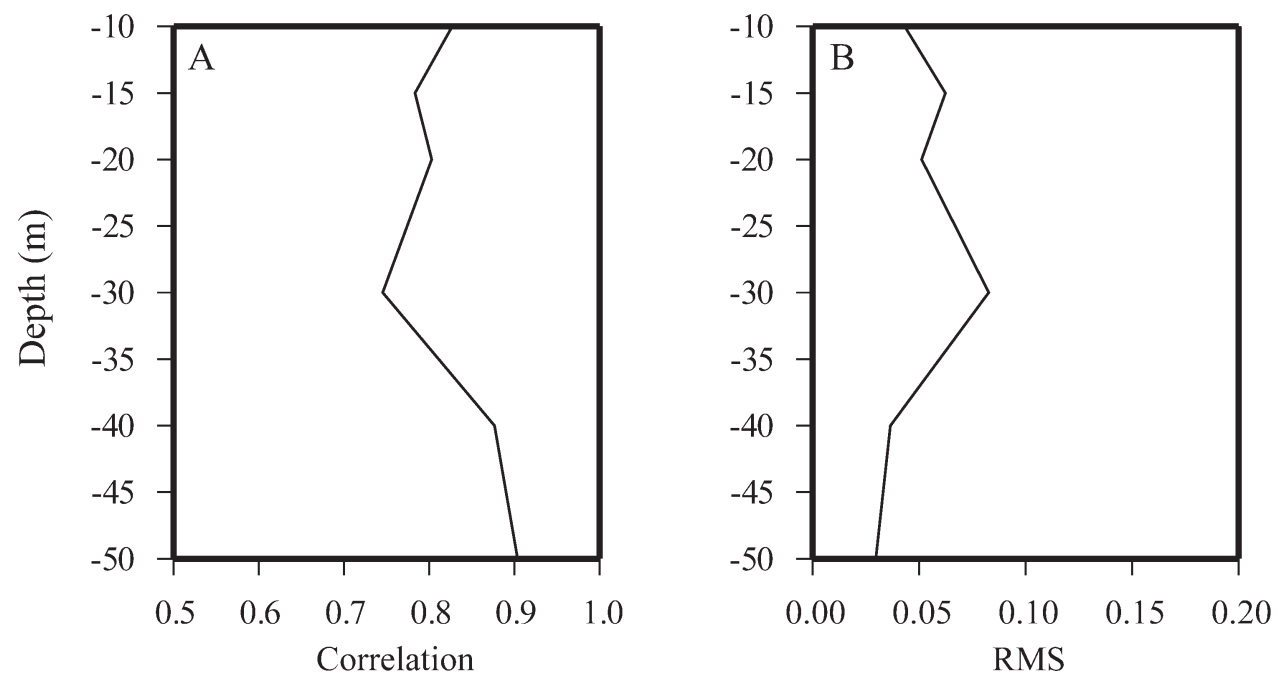

Fig. 4. (A) Correlation and (B) RMS differences as a function of depth as calculated between all the glider measurements and colocated ROMS reanalyses as shown in Fig. 3 .

the temperature and salinity comparisons, the time evolution of the velocities in the reanalysis is reasonably realistic. Also shown in Fig. 5 in the lower panel is the meridional velocity evolution obtained in a parallel ROMS simulation without any data assimilation. Without data assimilation, the time evolution is less faithful to observations than the reanalysis. In particular, the northward flow during mid-August is substantially overestimated. This demonstrates the effect of the data assimilation scheme.

To complement the point measurement of the mooring ADCP presented previously, surface currents measured by the HF radar are shown here to provide the spatial distribution of the surface flow over the entire Monterey Bay (Paduan and Rosenfeld 1996). A 33-h filter was applied to both the hourly HF radar data and the model simulation in order to remove tidal currents on the diurnal and semidiurnal time scales. Figure 6 shows a snapshot of this filtered data for 07 August and the correspondingly filtered surface current vectors from the ROMS reanalysis. On this day, both observations and reanalysis show good agreement in the equatorward moving currents in the outer and inner parts of the bay and relatively weak flow in the middle of the bay (especially near the M1 mooring).

Salinity distribution and propagation pathways-During summer, the circulation in the Monterey Bay region is characterized by two alternating states. The upwelling state, which prevails most of the time, is marked by centers of relatively cold and salty water to the north (near Pt. Año Neuvo) and south (near Pt. Sur) of the bay. These upwelling centers are generated by upwelling favorable winds blowing from north to south. During strong upwelling events, a band of cold and salty water often extends across the mouth of the bay (Rosenfeld et al. 1994). The relaxation states, which are usually brief, occur when the upwelling favorable winds weaken significantly or even reverse direction. During these times, the temperature and salinity distributions within the bay are more uniform with generally warmer and fresher waters.
In order to describe the synoptic evolution of the Monterey Bay temperature and salinity during the summer season, a REMUS AUV was deployed on a repeated transect through the northern half of the Monterey Bay along $122^{\circ} \mathrm{W}$ (or $238^{\circ} \mathrm{E}$ ) longitude from approximately Santa Cruz $\left(36.94^{\circ} \mathrm{N}\right)$ to approximately the middle of the bay $\left(36.74^{\circ} \mathrm{N}\right)$ for a period of $9 \mathrm{~d}, 10-17$ August (Fig. 1B; Moline et al. in press; Blackwell et al. in press). During this period, a strong upwelling event that developed in early August continued through 20 August. Figure 7 shows the $9-\mathrm{d}$ mean salinity cross section $\left(0-40 \mathrm{~m}, 36.74-36.92^{\circ} \mathrm{N}\right)$ from the REMUS observations (Fig. 7A) and the ROMS reanalysis (Fig. 7B). Also shown in bold are density contours. Excluding the northernmost and southernmost ends of the cross section, the mean fields from both model and observations show similar, nearly monotonic increases of salinity with depth, though the reanalysis is somewhat saltier.

In order to compare the time evolutions, we present salinity anomalies from the respective means shown in Fig. 7 in all subsequent cross sections. Figure 8 shows the cross sections of salinity anomalies with density contours overlaid for 10 August from REMUS (Fig. 8A) and the ROMS reanalysis (Fig. 8B). The most prominent feature is the subsurface negative anomaly in the middle of the cross section, roughly halfway between Santa Cruz and the middle of the bay. This feature appears with similar structure in both the observations and the reanalysis. The strongest anomalies, which approach 0.2 in the observations and exceed 0.2 in the reanalysis, are near $30 \mathrm{~m}$ below the surface (along the $24.85 \mathrm{~kg} \mathrm{~m}^{-3}$ isopycnal) in the observations and between 30 and $40 \mathrm{~m}$ in the reanalysis (along the $25 \mathrm{~kg} \mathrm{~m}^{-3}$ isopycnal), though anomalies greater than 0.1 are present throughout the vertical domain (5$40 \mathrm{~m}$ ) in the middle of the cross section.

As noted previously, in the reanalysis the maximum negative salinity anomaly on 10 August is located around the $25 \mathrm{~kg} \mathrm{~m}^{-3}$ density layer. We examine next the reanalysis salinity and velocity fields along the constant 

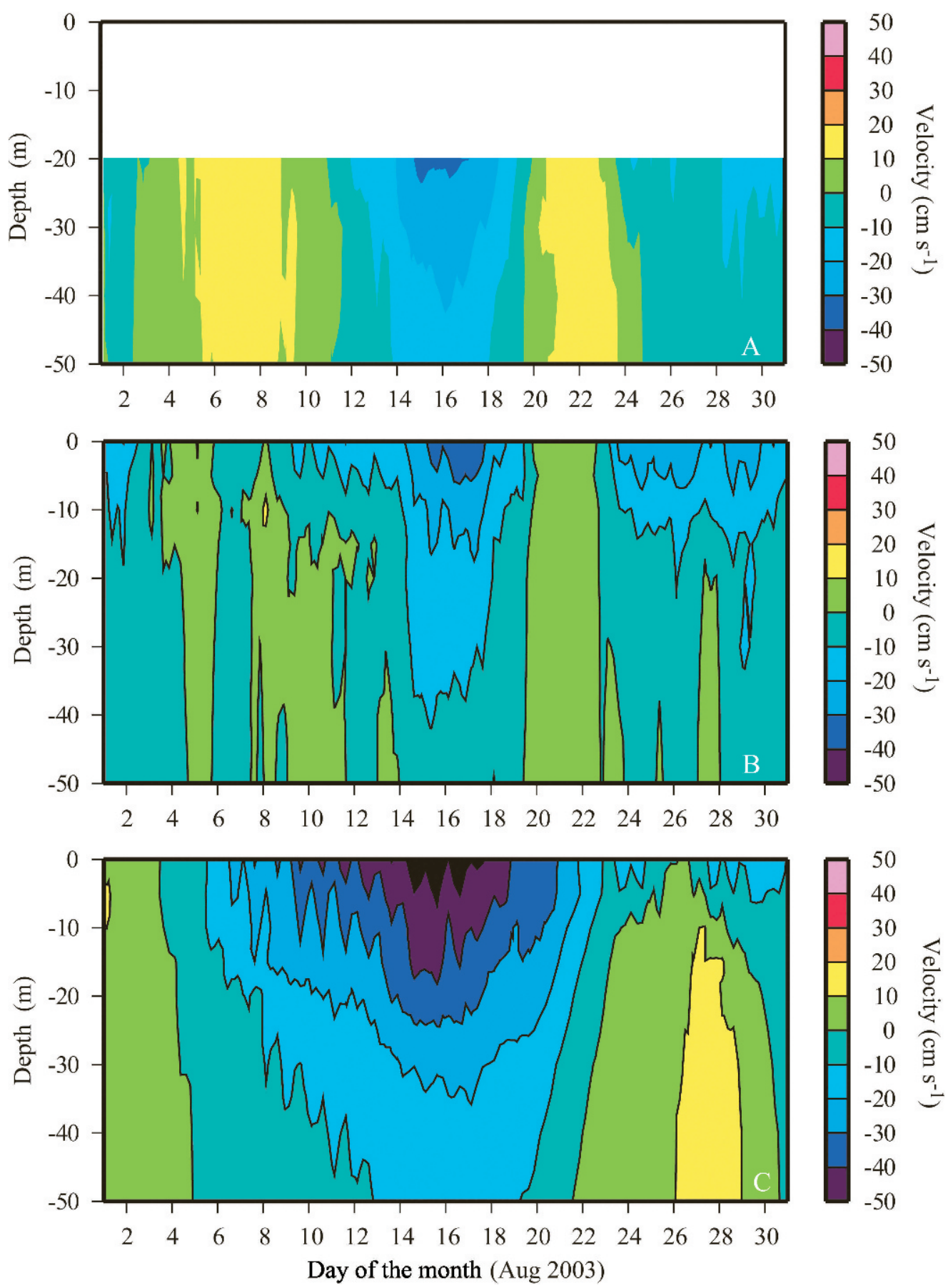

Fig. 5. Time-depth cross sections of the meridional currents at the $\mathrm{M} 1$ mooring location $\left(36.76^{\circ} \mathrm{N}, 122^{\circ} \mathrm{W}\right)$ as derived from $(\mathrm{A})$ the ADCP measurement, (B) the colocated ROMS reanalysis, and (C) ROMS simulation without data assimilation.

density (or isopycnal) surface of $25 \mathrm{~kg} \mathrm{~m}^{-3}$ on the days prior in order to determine the source of the low salinity waters and their subsequent propagation pathways. Figure 9 shows horizontal maps of salinity anomalies (departures from the 10-17 August mean) and current vectors on the $25 \mathrm{~kg} \mathrm{~m}^{-3}$ isopycnal surface for each day (daily means are shown) from 05 August through 10 August. On 05 August, as seen in Fig. 9, the northern part of the bay is covered by positive salinity anomalies, and there is a northward moving current across much of the bay along $122^{\circ} \mathrm{W}\left(238^{\circ} \mathrm{E}\right)$. This current persists with only minor changes in strength and structure through 09 August and is seen to transport lower-salinity water (negative anomalies) from the south and west northward into the bay on 06 and 07 August. These negative anomalies move into the northern half of the bay by 08 August, persist there through 10 August, and then gradually decay (not shown). Thus, it appears that these lower-salinity waters originate 


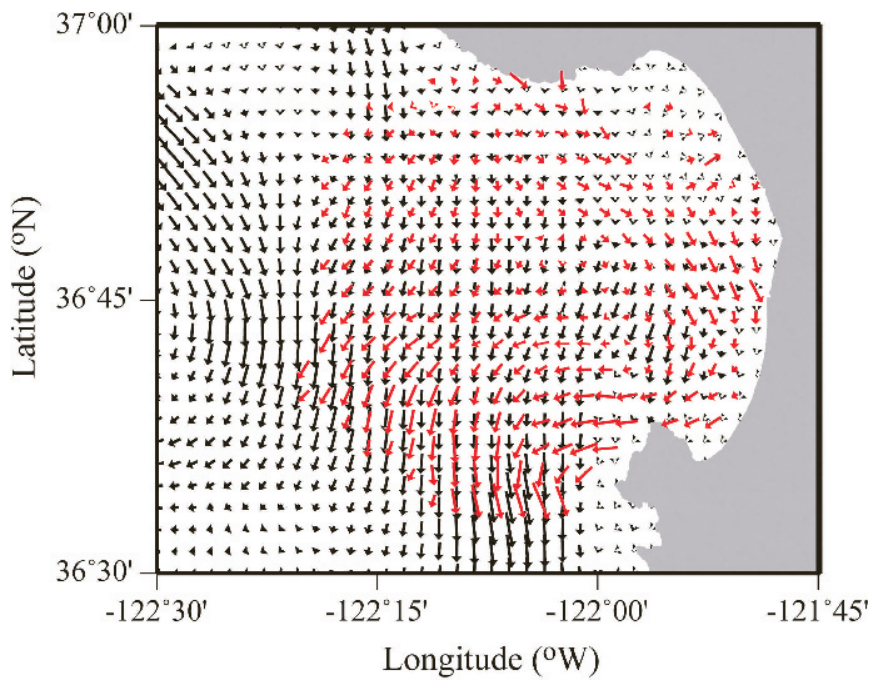

Fig. 6. Map of HF radar observed surface currents (red arrows) and ROMS reanalysis surface currents (black arrows) for 07 August 2003. to the south and west of the bay and are transported northward by a subsurface poleward flowing current.

In this first case study, we attempted to determine how realistic these simulated features of the isopycnal reanalysis fields are by comparing the ROMS reanalysis against the existing observations. Because of the limited observations, particularly for the velocity fields, we have to treat our diagnosed subsurface salinity source and propagation pathways as a hypothesis that can be tested in the future. We therefore emphasize here that extended studies using the REMUS AUV to collect subsurface spatial data combined with a 3D assimilative ocean model would provide an effective means to test this hypothesis.

Guided glider deployment and effect on model simulations-Motivated by the success of the 2003 field experiment that integrated the AUV measurement with the 3D modeling studies, a follow-on field experiment was conducted in Monterey Bay during August 2006. The focus of this experiment was the region of upwelling located off Pt. Año Nuevo just north of Monterey Bay with the observational assets deployed within a localized area (Fig. 1D). The primary observational assets were a fleet

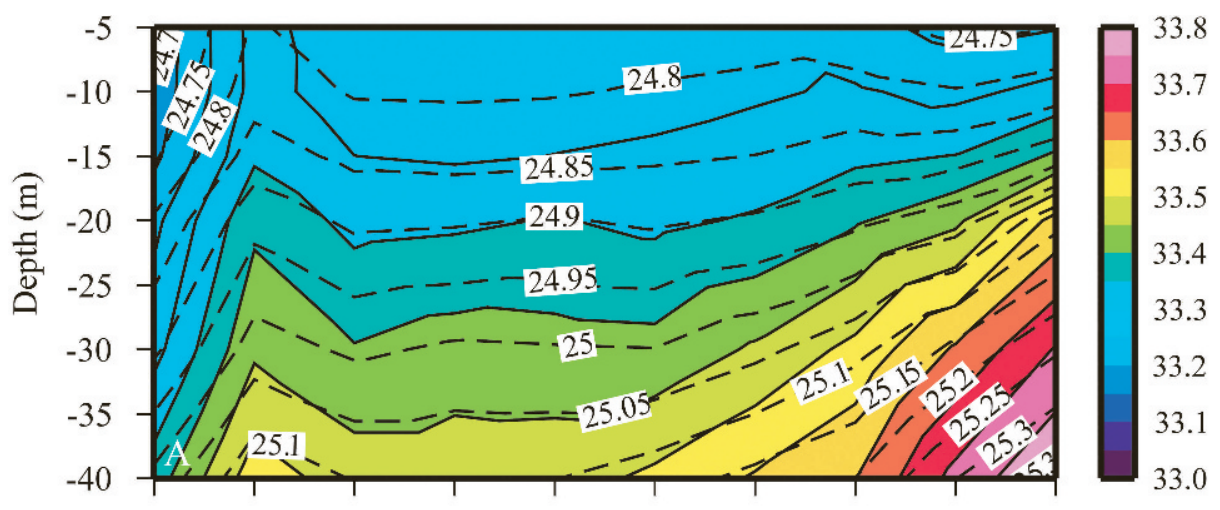

莺

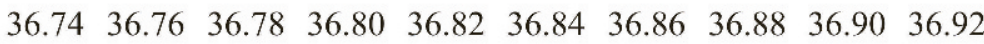

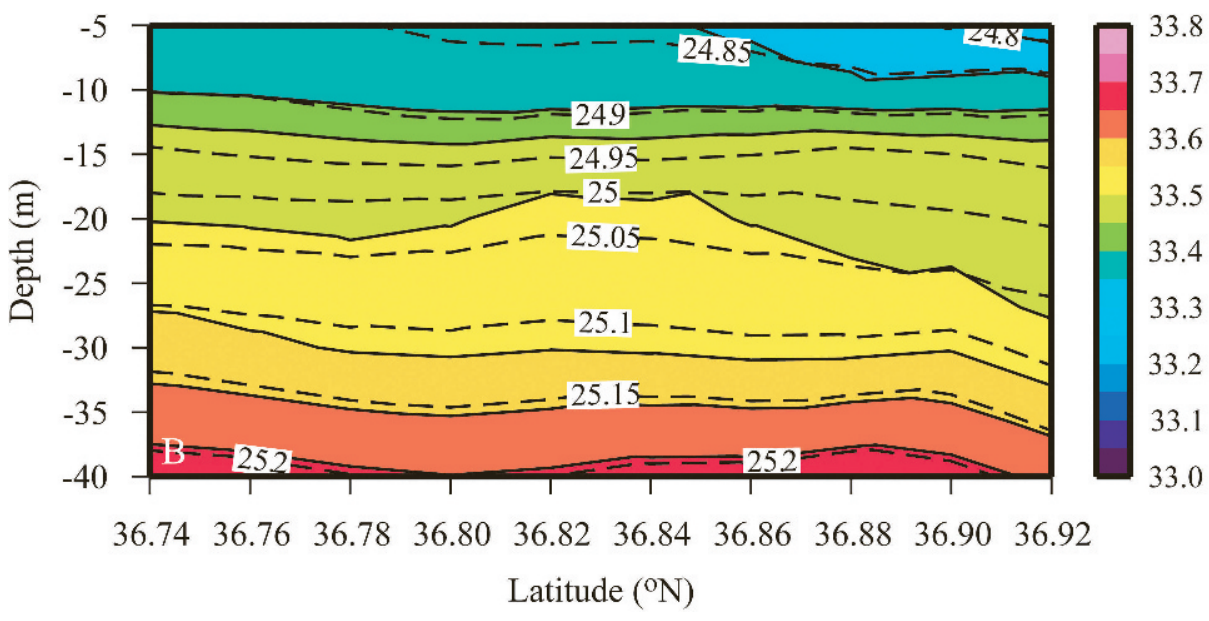

苛

Fig. 7. Eight-day mean (10-17 August 2003) vertical cross sections along $122^{\circ} \mathrm{W}$ of salinity (dashed lines, colored shading) and density $\left(\mathrm{kg} \mathrm{m}^{-3}\right.$, solid lines) from (A) REMUS AUV observations and (B) ROMS reanalysis. 


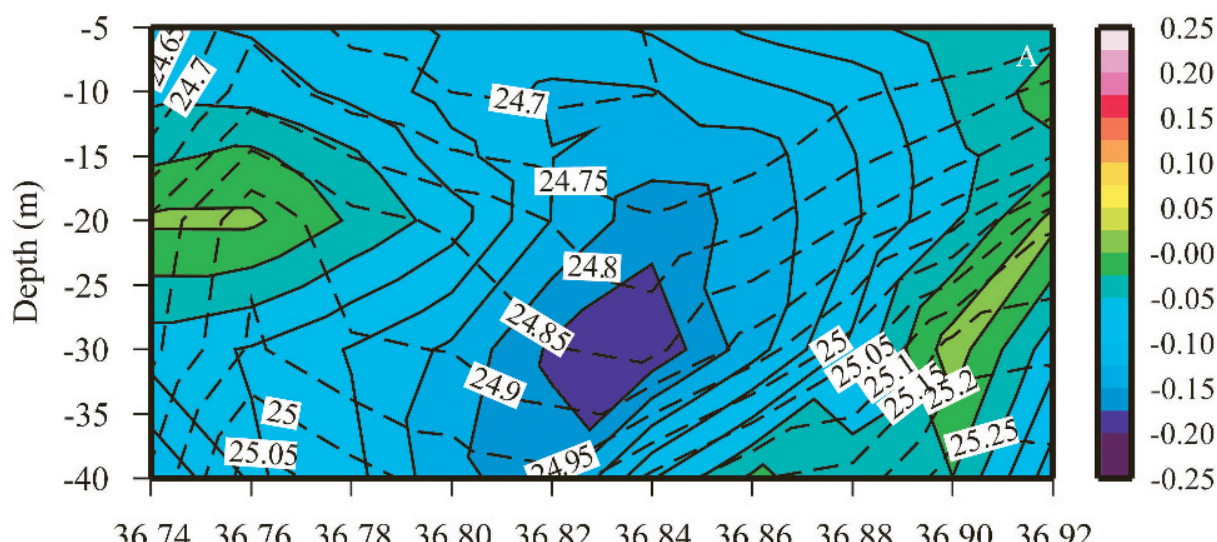

\section{芦.}

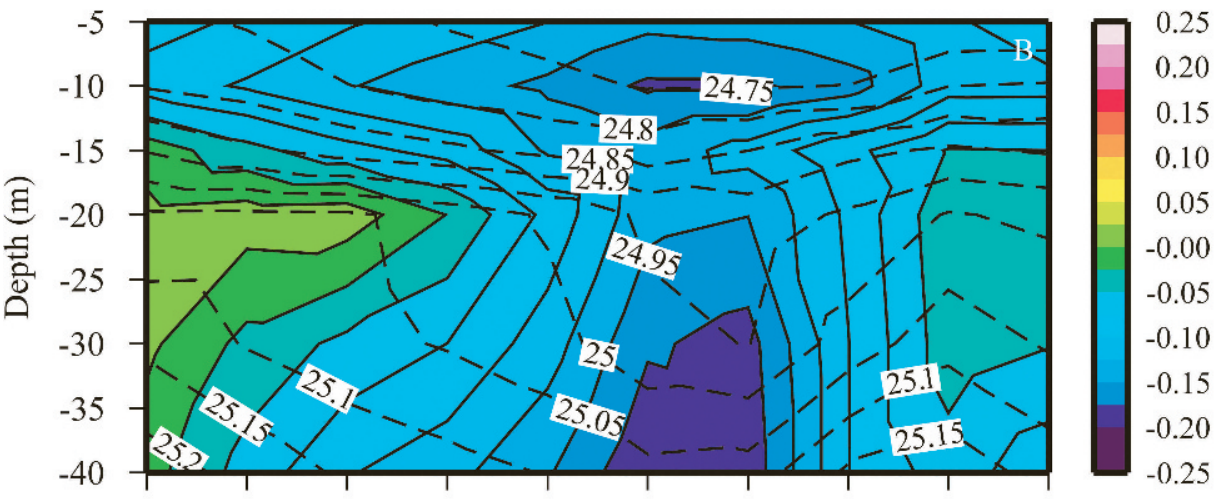

岂.

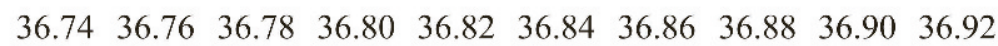

Latitude $\left({ }^{\circ} \mathrm{N}\right)$

Fig. 8. Vertical cross sections for 10 August 2003 along $122^{\circ} \mathrm{W}$ of salinity anomalies from the 8-d mean shown in Fig. 7 (dashed lines, colored shading) and density $\left(\mathrm{kg} \mathrm{m}^{-3}\right.$, solid lines) from (A) REMUS AUV observations and (B) ROMS reanalysis.

of Spray and Slocum gliders whose movements were coordinated by a Glider Coordinated Control System (GCCS; Paley et al. 2008). The GCCS specifies not only the desired track for each glider but also the desired relative motion of gliders on those tracks.

Since conditions in the observational region were affected by the larger-scale flow outside the region, the oversampling in the local environment was not optimal for the data-assimilating numerical models, like ROMS, producing real-time nowcasts and forecasts for the region. Thus, it was decided at the beginning of the experiment to deploy an additional Slocum glider, provided by RU COOL and operated by CalPoly and here called the CalPoly glider. This glider was operated in an area outside the region to demonstrate the effect of remote forcing by providing data on the larger scales for the numerical models. We present here the effect on the ROMS model performance of including this additional CalPoly glider data in the assimilation that produced the ROMS analysis for the first week of August 2006.

More than a dozen Spray and Slocum gliders were deployed in the upwelling center off Pt. Año Nuevo during the August 2006 intensive observing period (see Fig. 1D).
Figure 1D also shows the trajectory of this additional CalPoly glider deployed during the first week of August 2006 when profiles of temperature and salinity were taken along a line extending offshore just north of the observational box. Figure 10 shows the RMS differences in temperature and salinity between all glider measurements within the observational box and the colocated ROMS reanalysis values. Two curves are shown, one for the ROMS reanalysis that does not assimilate the CalPoly glider data and another for the reanalysis that does assimilate the CalPoly glider data. The reanalysis that includes the glider data shows better agreement (i.e., smaller RMS errors) with the gliders within the observational box. The improvement is greatest near the surface (above $50 \mathrm{~m}$ ) and more pronounced for salinity than for temperature (salinity errors are reduced by one-half in the upper $50 \mathrm{~m}$ ). It is somewhat surprising that the model performance depends so strongly on a single glider data. This reflects, at least in part, the scarcity of salinity observations outside the intensive observational domain to provide the larger scale circulation. We therefore conclude that careful consideration on regionally distributed resources, especially in the "upstream" condition, is important in the design of these experiments. 
Salinity
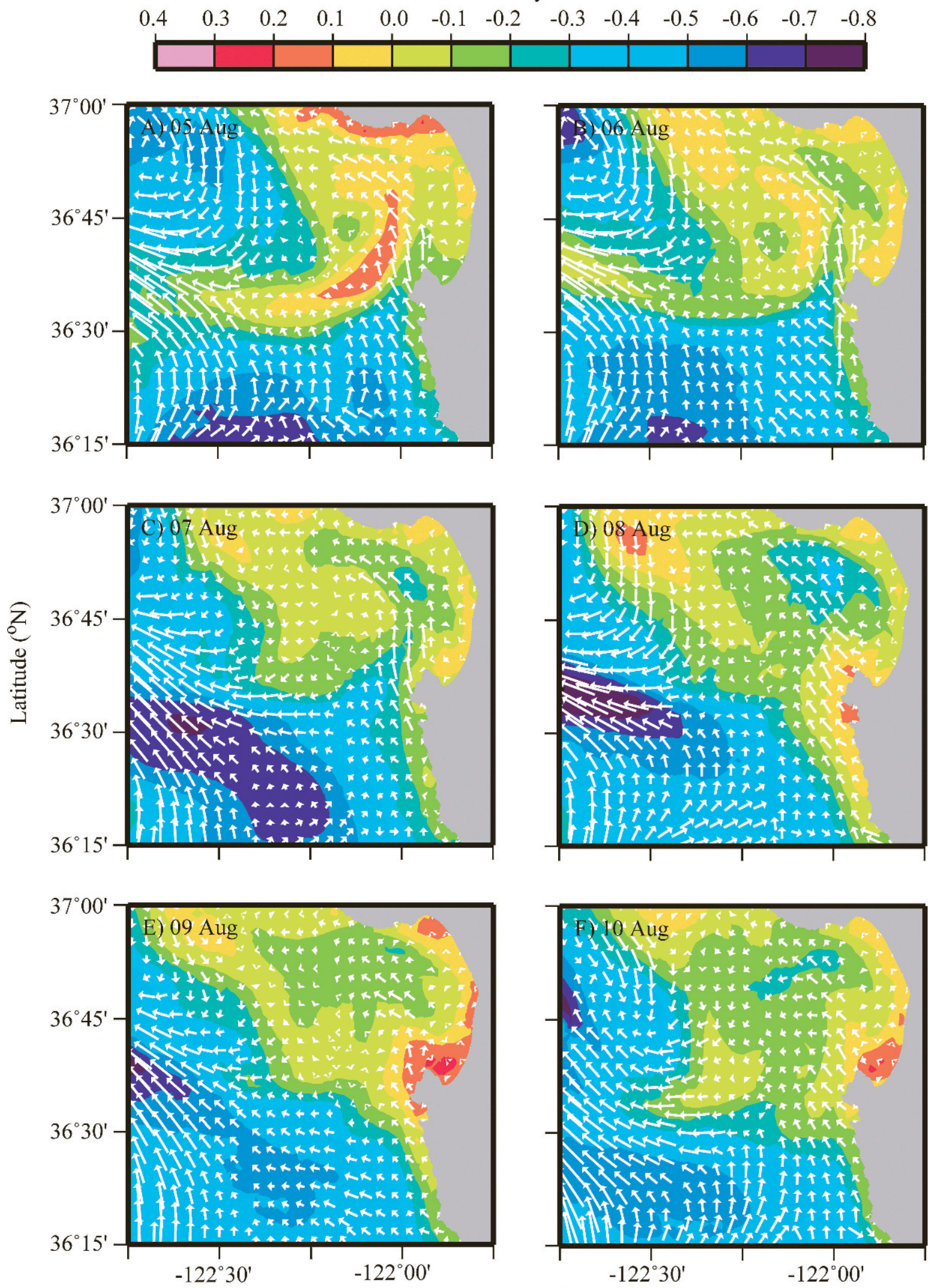

Longitude $\left({ }^{\circ} \mathrm{W}\right)$

Fig. 9. Daily maps of ROMS salinity anomalies from the 10-17 August mean and current vectors on the $25 \mathrm{~kg} \mathrm{~m}^{-3}$ isopycnal surface for (A) 05, (B) 06, (C) 07, (D) 08, (E) 09, and (F) 10 August 2003. 

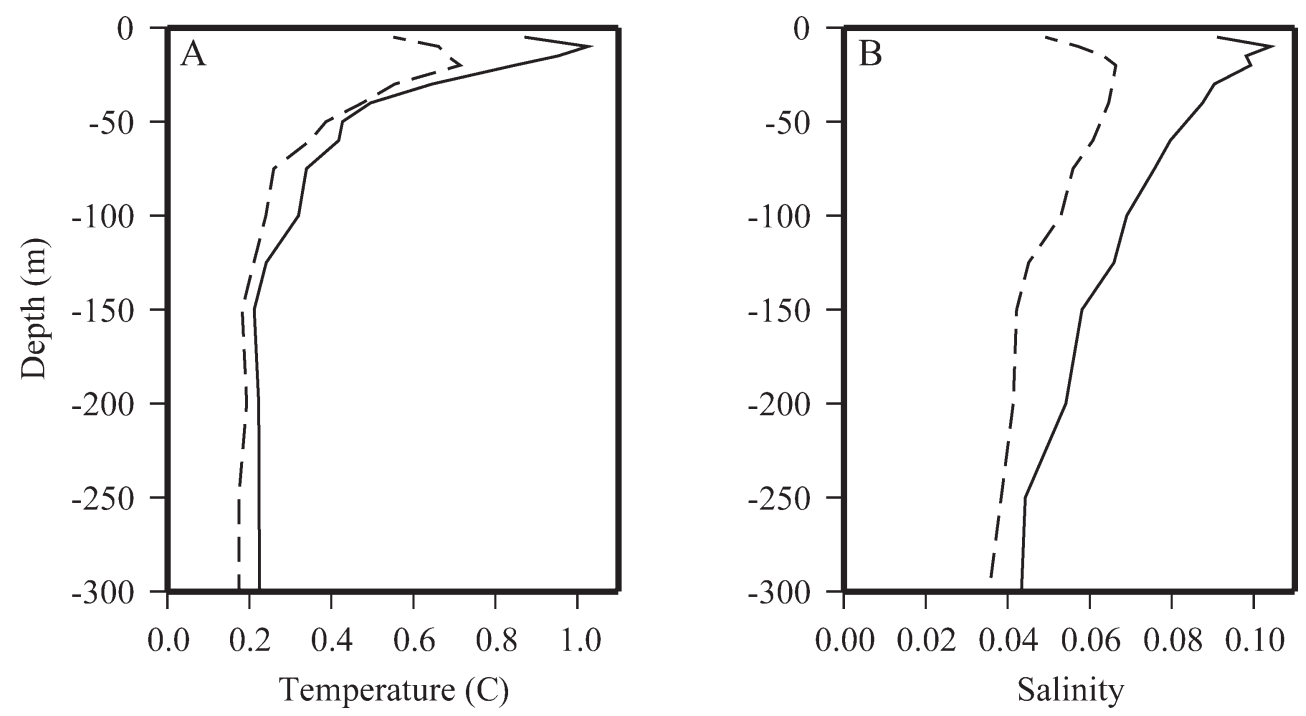

Fig. 10. ROMS reanalysis RMS errors in (A) temperature and (B) salinity with (solid line) and without (dashed line) assimilating the CalPoly glider data.

Targeted observations - Overall, the significant positive effect of assimilating the CalPoly glider data suggests that the deployment of glider observations can be quite effective in improving model predictions. This effectiveness may be maximized if the observations are "targeted" based on some objective guidance that is derived from models. Beginning in the second week of August 2006, guidance from the ETKF (Bishop et al. 2001) was produced in real time during the ASAP field experiment. The ETKF exploits uncertainty and dynamics of the flow via the covariance structure produced by the ensemble and combines this uncertainty with a data assimilation scheme to identify optimal locations for sampling (Majumdar et al. 2002). Formally, the ETKF guidance represents the reduction in prediction error variance within a given region, plotted as a function of the observation location. During 2006, the ETKF was based on an ensemble of 32 ROMS forecasts, in which 32 different initial conditions were cycled via the "breeding" method of Toth and Kalnay (1993). The ensemble required $10 \mathrm{~d}$ of spin-up (increasing the number of forecasts and stabilizing the variance), and therefore ETKF guidance was not available until the second week of August. The ETKF guidance as shown in Fig. 11 is aimed at answering the following question: What are the optimal sampling locations of sea surface temperature (salinity) $1 \mathrm{~d}$ from now in order to reduce the errors in a subsequent 1-d ROMS prediction of temperature (salinity) within the black circular region? For the case of sampling at 03 UTC on 14 August 2006, the optimal locations for sampling temperature are broad, covering the northern part of Monterey
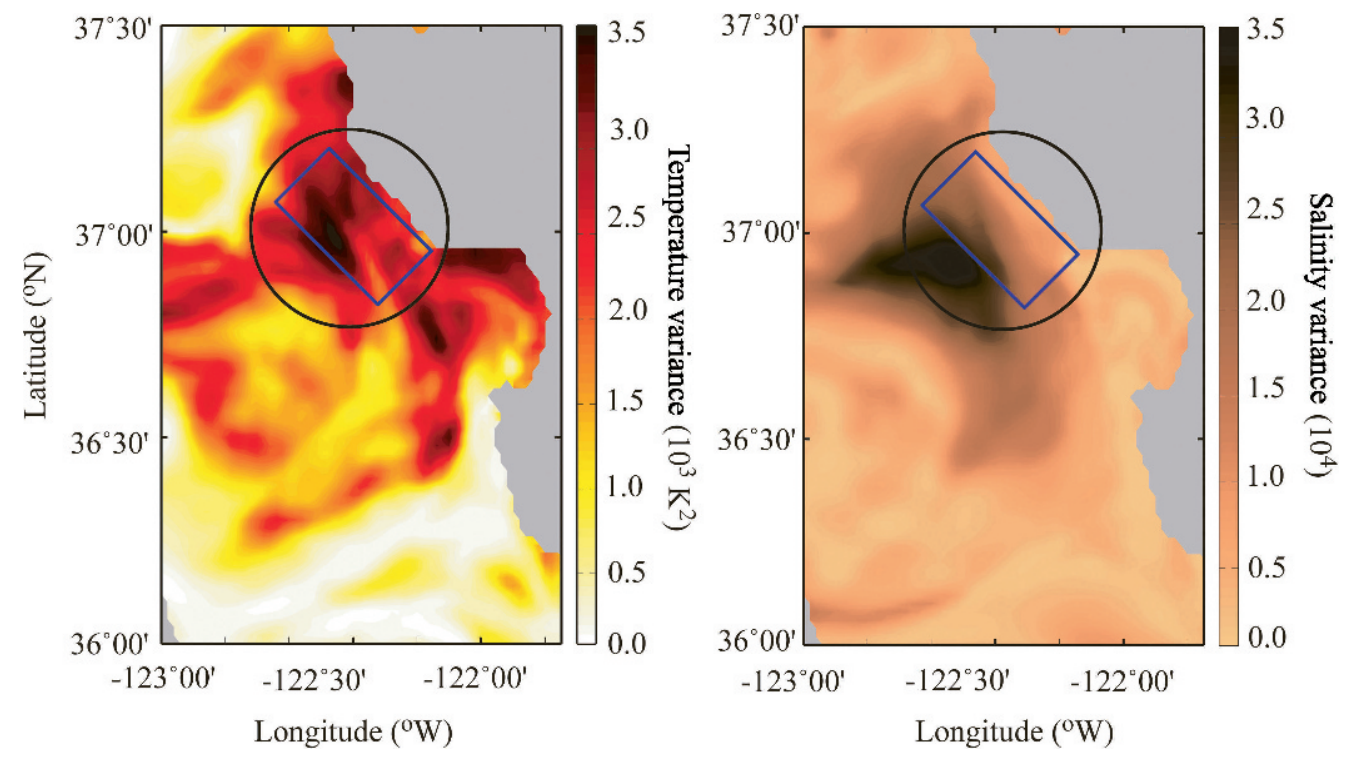

Fig. 11. ETKF guidance aimed at improving a 1-d ROMS prediction within the black circular domain. Darker shading corresponds to preferred locations for sampling targeted observations of (A) temperature and (B) salinity. 
Bay and the ASAP box. In contrast, a focused region of high-salinity gradient to the immediate southwest of the ASAP box is recommended for sampling salinity. Similar guidance at different depths was produced during the ASAP period and for 2 weeks in September 2006 to assist in the navigation of the CalPoly glider. This deployment was the first example of deploying a glider based on ETKF guidance. Thereby, the potential for real-time coordinated control of autonomous gliders using flow-dependent, model-based adaptive sampling guidance was demonstrated.

\section{Discussion}

We examined synergistic combinations of ALPS measurements and $3 \mathrm{D}$ assimilative ROMS output in the Monterey Bay, California, region. This was accomplished through two case studies during two different field experiments: the August 2003 AOSN-II and the August 2006 ASAP experiments.

In the first case study, the focus was on a subsurface salinity minimum in northern Monterey Bay revealed by the REMUS AUV observations during the AOSN-II experiment. A key question was whether the ROMS model analysis fields were realistic enough to be used for process studies in order to interpret the REMUS AUV observations. We first used a number of observations (e.g., gliders, moorings, and HF radar) to verify the analysis showing similar temperature and salinity distributions and circulation patterns. We concluded that the salinity distributions are sufficiently accurate, particularly the anomaly values, at least in part because of the assimilation of hydrographic data. The time evolution of the velocities in the reanalysis is also reasonably accurate. Further, the lower salinity values to the south and west of the bay identified by the REMUS AUV are well reproduced by the ROMS reanalysis. The ability of ROMS in reproducing both the salinity distributions and circulation patterns motivated us to use the complete 3D fields of temperature, salinity (therefore density), and velocity provided by the ROMS reanalysis to perform process studies with an attempt to identify the formation of the subsurface fresh waters discovered by the REMUS AUV and investigate their propagation pathways. Our results suggest that the lower-salinity waters originated to the south and west of the bay and were transported northward by a subsurface poleward-flowing current.

In the second case study, the effectiveness of assimilating glider observations in improving the ROMS analysis fields during the first week of the August 2006 ASAP experiment was investigated. A significant improvement was demonstrated by a single glider deployed outside the intensive observational domain. The effect is particularly prominent for the salinity fields, reflecting the scarcity of salinity observations. It should be pointed out that the positive effect can be attributed mostly to the deployment location outside the intensive observational domain. Because of the large number of gliders deployed in the relatively small intensive observational domain and the small decorrelation scale for the nearshore property distributions, the assimilation model was well constrained within the observational domain. To add additional gliders within the observational domain would yield only marginal improvement in the model nowcast and forecast. Outside the observational domain, on the other hand, there were very few salinity profile measurements, only from moorings and Argo profiling floats. Thus, the larger-scale circulation outside the intensive observational domain was poorly constrained. To add even a single glider outside the observational domain, therefore, shows a significant positive effect on the assimilation model. This suggests that targeted observations can be quite effective in designing and refining the ocean observing network. Candidate methodologies, such as the ETKF or adjoint-based techniques, require further investigation and evaluation to become an effective tool for real-time guidance.

In summary, our results demonstrated the utility and power of synergistic combinations of ALPS measurements and $3 \mathrm{D}$ assimilative ocean models. ALPS measurements will play a key role in the emerging NOAA IOOS and National Science Foundation's Ocean Observing Initiative. More sophisticated techniques for utilizing data and models synergistically should be explored. Such techniques include increasing model resolution in areas of interest identified by observing platforms (e.g., fronts, eddies, and water mass anomalies) and/or using model-based ensemble techniques to identify areas of uncertainty in the model nowcast and forecast to guide placement of observational assets. Similar to the nested modeling approach, nested deployment of observational assets including ALPS is also suggested.

\section{References}

Besiktepe, S. T., P. F. J. Lermusiaux, and A. R. Robinson. 2003. Coupled physical and biogeochemical data-driven simulations of Massachusetts Bay in late summer: Real-time and postcruise data assimilation, J. Mar. Sys. 40-41: 171-212.

Bishop, C. H., B. J. Etherton, and S. J. Majumdar. 2001. Adaptive sampling with the ensemble transform Kalman filter. Part I: Theoretical aspects. Mon. Weather Rev. 129: 420-436.

Blackwell, S. M., M. A. Moline, A. Schaffner, and G. Chang. In press. Defining sub-kilometer length scales in coastal waters. Cont. Shelf Res.

Cane, M., S. E. Zebiak, and S. C. Dolan. 1986. Experimental forecasts of El Nino. Nature 321: 827-832.

Chang, G. C., T. D. Dickey, O. Schofield, A. D. Weidemann, E. Boss, M. A. Moline, And S. M. Glenn. 2002. Nearshore physical forcing of bio-optical parameters in the New York Bight. J. Geophys. Res. 107: 3133, doi:10.1029/2001JC001018.

Chavez, F., J. T. Pennington, R. Herlien, H. Jannasch, G. Thurmond, And G. E. Friederich. 1997. Moorings and drifters for real-time interdisciplinary oceanography. J. Atmos. Oceanic Tech. 14: 1199-1211.

Curtin, T. B., J. G. Bellingham, J. Catipovic, and D. Webb. 1993. Autonomous oceanographic sampling networks. Oceanography 6: 86-94.

Hodur, R. M., And J. D. Doyle. 1999. The coupled ocean/ atmosphere mesoscale model prediction system (COAMPS). Coastal Ocean Prediction, Coastal and Estuarine Studies 56: 125-155.

Leonard, N. E., D. A. Paley, F. Lekien, R. Sepulchre, D. M. Fratantoni, and R. E. Davis. 2007. Collective motion, sensor, networks, and ocean sampling. Proc. IEEE 95: 48-74, doi:10.1109/JPROC.2006.887295. 
Li, Z., Y. Chao, J. C. McWilliams, and K. Ide. 2008. A threedimensional variational data assimilation scheme for the regional ocean modeling system: Implementation and Experiments. J. Geophys. Res. 103: C05002, doi:10.1029/ 2006JC004042. sional variational data assimilation scheme for the Regional Ocean Modeling System: Formulation. J. Atmos. Oceanic Tech.

Lovejoy, S., W. J. S. Currie, Y. Tessier, B. E. Claeroboudt, J. C. RofF, AND D. Schertzer. 2001. Universal multifractals and ocean patchiness: Phytoplankton, physical fields and coastal heterogeneity. J. Plankton Res. 23: 117-141.

Majumdar, S. J., C. H. Bishop, B. J. Etherton, and Z. Toth. 2002. Adaptive sampling with the ensemble transform kalman filter. Part II: Field program implementation. Mon. Weather Rev. 130: 1356-1369.

Moline, M. A., AND OTHERs. 2005. Remote environmental monitoring units: An autonomous vehicle for characterizing coastal environments. J. Atmos. Oceanic Tech. 22: 1798-1809.

- AND OTHERS. In press. Structure and interaction of coastal planktonic communities using bioluminescence. Deep-Sea Res.

Paduan, J. D., And L. K. Rosenfeld. 1996. Remotely sensed surface currents in Monterey Bay from shore-based HF radar (coastal ocean dynamics application radar). J. Geophys. Res. 101: 20669-20686, doi:10.1029/96JC01663.

Paley, D., F. Zhang, and N. E. Leonard. 2007. Cooperative control for ocean sampling: The glider coordinated control system. IEEE Transactions on Control Systems 16: 735-744.
Rosenfeld, L. K., F. Schwing, N. Garfield, and D. E. Tracy. 1994. Bifurcated flow from an upwelling center: A cold water source for Monterey Bay. Continental Shelf Research 14: 931-964.

Schofield, O., AND OTHERs. 2002. The long-term ecosystem observatory: An integrated coastal observatory. IEEE Journal of Oceanic Engineering 27: 146-154.

$\longrightarrow$, AND OTHERS. 2007. Slocum gliders: Robust and ready. Journal of Field Robotics 24: 473-485, doi:10:1002/rob. 20200.

Shchepetkin, A. F., and J. C. McWilliams. 1998. Quasimonotone advection schemes based on explicit locally adaptive dissipation. Mon. Weather Rev. 126: 1541-1580.

— AND - 2005. The regional oceanic modeling system: A split-explicit, free-surface, topography-following-coordinate ocean model. Ocean Modeling 9: 347-404.

Toth, Z., AND E. Kalnay. 1993. Ensemble forecasting at NMC: The generation of initial perturbation. Bull. Am. Meteorol. Soc. 74: 2317-2330.

Yoder, J. A., C. A. McClain, J. O. Blanton, and L. Oey. 1987. Spatial scales in CZCS-chlorophyll imagery of the southeastern U. S. continental shelf. Limnol. Oceanogr. 32: 929-941.

Zhang, F., And N. E. LeOnard. 2007. Coordinated patterns of unit speed particles on a closed curve. Systems \& Control Letters 56: 397-407, doi:10.1016/j.sysconle.2006.10.027.

Received: 3 October 2007 Accepted: 23 June 2008 Amended: 28 June 2008 